\title{
Mortalin peptides exert antitumor activities and act as adjuvants to antibody-mediated complement-dependent cytotoxicity
}

\author{
RITTA JUBRAN ${ }^{1}$, MORAN SAAR-RAY $^{1}$, ANNA WAWRUSZAK ${ }^{2}$, LEA ZIPOREN $^{1}$, \\ NATALIE DONIN $^{1}$, OSNAT BAIREY ${ }^{3}$ and ZVI FISHELSON ${ }^{1}$ \\ ${ }^{1}$ Department of Cell and Developmental Biology, Sackler Faculty of Medicine, Tel Aviv University, Tel Aviv 69978, Israel; \\ ${ }^{2}$ Department of Biochemistry and Molecular Biology, Medical University of Lublin, Lublin 20-093, Poland; \\ ${ }^{3}$ Institute of Hematology, Davidoff Cancer Center, Rabin Medical Center - Beilinson Hospital, Petach \\ Tikva 49100, and the Sackler Faculty of Medicine, Tel Aviv University, Tel Aviv 69978, Israel
}

Received February 20, 2020; Accepted June 9, 2020

DOI: $10.3892 / \mathrm{ijo} .2020 .5101$

\begin{abstract}
Cancer cells have developed numerous strategies to maintain their proliferative capacity and to withstand different kinds of stress. The mitochondrial stress-70 protein named glucose regulated protein 75 (GRP75), also known as mortalin, is an intriguing cancer pro-survival factor. It is constitutively expressed in normal tissues but is upregulated in many tumors, and was shown to be a cancer prognostic biomarker. Mortalin is an inhibitor of complement-dependent cytotoxicity (CDC) and may therefore protect cells from antibody-based immunotherapy. To target mortalin for cancer therapy, our laboratory designed several mortalin mimetic peptides with sequences predicted to be involved in mortalin binding to its client proteins. The peptides were synthesized with a C-terminal transactivator of transcription sequence. By using cell death methodologies, the mechanism of action of the mortalin mimetic peptides on cancer cells was studied. Two peptides in particular, Mot-P2 and Mot-P7, were found to be highly toxic to lymphoma and ovarian, breast and prostate carcinoma cells. The analysis of their mode of action revealed that they may induce, within minutes, plasma membrane perturbations and mitochondrial stress. Furthermore, Mot-P2 and Mot-P7 activated necrotic cell death, leading to plasma membrane perforation, mitochondrial inner membrane depolarization and decrease in ATP level. In addition, Mot-P7, but not Mot-P2, required extracellular calcium ions to fully mediate cell death and was partially inhibited by plasma membrane cholesterol. At sub-toxic concentrations, the two peptides moderately inhibited cancer cell proliferation and blocked cell cycle at G2/M. Both peptides may bind intracellularly to mortalin
\end{abstract}

Correspondence to: Professor Zvi Fishelson, Department of Cell and Developmental Biology, Sackler Faculty of Medicine, Tel Aviv University, 30 Chaim Levanon Street, Tel Aviv 69978, Israel

E-mail: lifish@tauex.tau.ac.il

Key words: mortalin, peptides, complement-dependent cytotoxicity, cell death, mitochondria and/or a mortalin-binding protein, hence knocking down mortalin expression reduced cell death. Combining treatment with Mot-P2 or Mot-P7 and CDC resulted in increased cell death. This study identified highly cytotoxic mortalin mimetic peptides that may be used as monotherapy or combined with complement-activating antibody therapy to target mortalin for precision cancer therapy.

\section{Introduction}

Acquired resistance of tumor cells to cell death is crucial in tumorigenesis and a major obstacle to tumor therapeutic strategies (1). Resistance to cell death may be attributed to several abnormally expressed genes. One such gene is Heat Shock Protein Family A Member 9 (HSPA9) coding for mortalin, the mitochondrial stress protein 70 also known as glucose regulated protein 75 (GRP75), which is an essential member of the heat shock proteins 70 family $(2,3)$. Mortalin expression is upregulated in tumors and its expression level is positively correlated with tumor aggressiveness and metastasis (4-7). Furthermore, soluble mortalin has been detected in the serum of patients with colorectal cancer and its level is positively correlated with patients' poor prognosis $(8,9)$. Mortalin possesses numerous crucial functions, including in intracellular trafficking and protein quality control (10). Being located in the mitochondria, mortalin is involved in mitochondrial biogenesis and regulation of mitochondrial membrane potential, export and import of mitochondrial proteins and energy generation $(10,11)$. Furthermore, mortalin protects tumor cells from apoptosis by chelation of p53 (3). A previous study from our laboratory demonstrated that mortalin protects tumor cells from antibody-dependent complement-mediated cytotoxicity (CDC) by promoting the removal of the membrane attack complex (MAC; C5b-9) from complement-attacked cells via released vesicles (12). In addition, by directly binding to the complement proteins $\mathrm{C} 8$ and $\mathrm{C}$, mortalin can inhibit MAC assembly and incorporation into membranes, which is a pivotal step in CDC $(12,13)$. Knockdown or inhibition of mortalin by small interfering (si)RNA or MKT-077, respectively, increases cell sensitivity to CDC $(13,14)$. Accumulating evidence reported that the expression level and function of 
mortalin are altered in tumor cells, resulting in immune resistance and tumor progression. Subsequently, mortalin has been considered as a potential target for cancer therapy. The present study hypothesized that synthetic peptides which have amino acid sequences derived from mortalin's sequence could block the protective interactions of mortalin with its client proteins and might trigger either spontaneous and/or elevated immune cell death. In the present study, mimetic peptides derived from mortalin sequence were generated and their efficacy to induce cancer cell death was tested, as single agents and as adjuvants to CDC. To promote peptide entry into cells, a transactivator of transcription $(T A T)$ sequence $(15,16)$ was added to their C-terminal domain. This study evaluated the anti-cancer toxic activity and underlying mechanism of several mimetic mortalin peptides.

\section{Materials and methods}

Cell culture. The human erythroleukemia cells K562 and the Raji and Ramos lymphoma cells were grown in RPMI-1640. The mantle cell lymphoma cells Z-138 were grown in Iscove's modified Dulbecco's medium. The human ovarian carcinoma cells SKOV3, the human breast carcinoma cells T47D and the human prostate carcinoma cells PC3 were cultured in Dulbecco's Modified Eagle Medium. All growth media (Sigma-Aldrich; Merck KGaA) were supplemented with $10 \%$ fetal calf serum (Gibco; Thermo Fisher Scientific, Inc.), glutamine and pyruvate (Bio-Rad Laboratories, Inc). Cells were purchased from the American Type Culture Collection and were mycoplasma-free.

Blood samples $(5 \mathrm{ml})$ were collected from patients with B-cell chronic lymphocytic leukemia (B-CLL) and from healthy volunteers and placed in EDTA-containing plastic tubes. This study was approved by the Helsinki Committee of the Rabin Medical Center, Petach Tikva, Israel and informed consent was provided by all participants. Blood was diluted 2-fold with Hanks' Balanced Salt Solution (Sigma-Aldrich; Merck $\mathrm{KGaA}$ ) and placed on top of $15 \mathrm{ml}$ Lymphoprep (Stemcell Technologies, Inc.) in conical plastic tube and centrifuged at $400 \mathrm{x}$ g for $30 \mathrm{~min}$ at room temperature. The upper layer was aspirated and the peripheral blood mononuclear cell (PBMC) layer was collected. PBMC were washed, resuspended in HBSS, counted and kept on ice until used. Most of the cells isolated from patients were B-CLL cells.

Reagents. Peptides were purchased from either Mimotopes, Genemed Synthesis, Inc. or Blavatnik Research Center (Tel-Aviv University). The sequences of the peptides were chosen following computational modelling of human mortalin structure (Compugen Ltd.), and predicting protein interaction sites in the $\mathrm{N}$-terminal nucleotide-binding domain (NBD, 52-433) or the C-terminal substrate-binding domain (SBD, 434-679) of mortalin. A TAT sequence corresponding to the human immunodeficiency virus type 1 entry sequence RKKRRQRRR was added at the $\mathrm{C}$-terminus of each peptide. A biotin was added at the N-terminus domain of the peptides. Peptides were purified by HPLC to $>90 \%$ purity, tested by mass spectrometry and kept lyophilized at $-20^{\circ} \mathrm{C}$. Fresh stock peptide solutions $(2-10 \mathrm{mM})$ were prepared in DMSO. The sequences of the peptides were as follows: Mot-P2, PSQIGAFVLMKMKETAENYL (mortalin no. 163-182, NBD);
Mot-P7, GEDFDQALLRHIVKEFKRET (mortalin no. 275-294, NBD); Mot-P8, NMALQRVREAAEKAKSEL (mortalin no. 302-319, NBD); Mot-P10, RAQFEGIVTDLIRRTIA (mortalin no. 348-364, NBD); Mot-P14, MVKNAEKYAEEDR (mortalin no. 561-573, SBD); Mot-P16, FKDQLPADECN KLKEEISKMRELLA (mortalin no. 599-623, SBD); and scrambled peptide, KERYNEAKEDMVA.

Normal human serum (NHS; $3 \mathrm{H}$ biomedical AB) was stored at $-70^{\circ} \mathrm{C}$. A polyclonal anti-human $\mathrm{C} 3$ antiserum was prepared in goats by subcutaneous injection of human C3. First inoculation was done with Complete Freund's adjuvant, followed by three more subcutaneous injections with Incomplete Freund's adjuvant. Mouse anti-mortalin antibody was purchased from StressMarq Biosciences, Inc. (cat. no. SMC-133) or Abcam (cat. no. ab94668), and mouse anti-actin antibody was provided by EMD Millipore (cat. no. MAB1501). Peroxidase-conjugated goat anti-mouse IgG (cat. no. 115-035-003), FITC-conjugated rabbit anti-goat IgG (cat. no. 305-095-003), AlexaFluor 488-conjugated anti-human IgG (cat. no. 109-545-003) and FITC-conjugated goat anti-mouse IgG (cat. no. 115-095-003) were purchased from Jackson ImmunoResearch Laboratories, Inc. Mouse monoclonal antibody directed to a neoepitope in human C5b-9 (clone aE11) was from Hycult Biotech (cat. no. HM2167). Mouse anti-human CD46 (cat. no. BLG-352404), anti-human CD55 (cat. no. BLG-311302) and anti-human CD59 (cat. no. BLG-304702) monoclonal antibodies were from BioLegend, Inc. Monoclonal anti-CD20 antibody (Rituximab) was from Roche Pharmaceutical Ltd., (cat. no. RO 45-2294).

JC-1 mitochondrial staining kit, staurosporine (STS), methyl- $\beta$-cyclodextrin $(\mathrm{M} \beta \mathrm{CD})$, filipin III and bovine serum albumin (BSA) were purchased from Sigma-Aldrich; Merck KGaA. The caspase inhibitor Q-VD-OPh (QVD) was from R\&D Systems and Annexin V Apoptosis Detection Kit was from Thermo Fisher Scientific, Inc. DCFDA- Cellular ROS Detection Assay kit was from Abcam. Cell Cycle Kit was from Merck KGaA. Fluorescein (DTAF)-conjugated streptavidin was from Jackson ImmunoResearch Laboratories, Inc. TMB substrate and TMB Stop solution were from SouthernBiotech. The CytoTox-ONE lactate dehydrogenase (LDH) release kit and CellTiter-Glo luminescent cell viability assay were from Promega Corporation. N-acetyl cysteine (NAC) was from Enzo Life Sciences.

SMARTpool siRNA for RNA interference was from GE Healthcare Dharmacon, Inc. The human HSPA9 gene (mortalin) targeting sequences were a mixture of GAGGUGAAAUCCACAAAUG, GACUAUCGC UCCAUGCCAA, CCUAUGGUCUAGACAAAUC and AAACGCAAGUGGAAAUUAA. The non-specific siRNA targeting sequences were UAAGGCUAUGAAGAGAUAC, AUGUAUUGGCCUGUAUUAG, AUGAACGUGAAUUGC UCAA and UGGUUUACAUGUCGACUAA.

Evaluation of cell death, ATP synthesis and cell cycle analysis. Cancer cells were incubated with mortalin peptides $(5-100 \mu \mathrm{M})$ for $30 \mathrm{~min}\left(0.25 \times 10^{6}\right.$ cells $/ 100 \mu \mathrm{l}$ in $12 \times 75-\mathrm{mm}$ glass test tubes) or overnight $\left(0.25 \times 10^{6}\right.$ cells $/ 200 \mu \mathrm{l}$ in 24-well plates) at $37^{\circ} \mathrm{C}$. Adherent carcinoma cells were first detached from plate by trypsinization and washed with HBSS before treatment with peptides. Next, cells were 
labeled with propidium iodide (PI) or DAPI, both at $1 \mu \mathrm{g} / \mathrm{ml}$, and immediately analyzed by Cytoflex Flow Cytometer (Beckman Coulter). Cell death was calculated after quantifying PI/DAPI-negative, viable cells in a $30 \mathrm{sec}$ flow. Viable cell counts in negative control samples were defined as Total cells. The quantification of cell death was performed as follows: Cell death $(\%)=[$ (total cells- the number of viable cells in experimental) / total cells] x 100. Alternatively, following peptide treatment, cells were washed, mixed with $0.02 \%$ trypan blue in isotonic buffer and percent cell death was determined after counting live/dead cells in a hemocytometer under a light microscope. Percentage of cell death for control cells incubated without a peptide (C) was subtracted from that of experimental peptide-treated cells (E) to calculated the final percentage of dead cells as follows: Cell Death $=[(\mathrm{E}-\mathrm{C}) /(100-\mathrm{C}) \mathrm{x}$ 100]. After treatment, cells were also labelled with annexin-V-FITC (Thermo Fisher Scientific, Inc.) to detect changes in plasma membrane asymmetry and permeability.

Cell death was also evaluated according to $\mathrm{LDH}$ release following the manufacturers' instructions. Briefly, cells were seeded at a density of $5 \times 10^{4}$ cells/well in $50 \mu 1$ of culture medium in a 96-well plate and were treated with mortalin peptides at various concentrations for $30-60 \mathrm{~min}$ at $37^{\circ} \mathrm{C}$. A negative control included solvent (DMSO) treatment. For total LDH release (representing death of all cells, i.e., $100 \%$ cell death), cells were treated with the kits' lysis solution. Cells at room temperature were mixed with CytoTox-ONE reagent for $10 \mathrm{~min}$ at $22^{\circ} \mathrm{C}$. Next, a stop solution was added and fluorescence emission at $590 \mathrm{~nm}$ (excitation at $560 \mathrm{~nm}$ ) was measured in a SpectraMAX M5 microplate reader and corresponded to the LDH release. The percentage of cell death was calculated according to the following equation: (LDH released by peptide - LDH released by DMSO) / (total LDH Released - LDH released by DMSO) x 100 .

To determine the peptide's effect on cellular ATP levels, cells were treated with the peptides at various concentrations for $30 \mathrm{~min}$ at $37^{\circ} \mathrm{C}$. ATP level was quantified with the CellTiter-Glo kit according to the manufacturers' instructions. Briefly, luminescence level, representing ATP level, was recorded in a microplate reader in peptide-treated and DMSO-treated cells, and the percentage of ATP level in peptide-treated relative to DMSO-treated cells was calculated.

To identify changes in cell cycle, cells were treated with peptides at various concentrations for $36 \mathrm{~h}$ at $37^{\circ} \mathrm{C}$. Cells were washed with PBS, mixed with $70 \%$ ice-cold ethanol and fixed for at least $2 \mathrm{~h}$ at $-20^{\circ} \mathrm{C}$. Subsequently, cells were labeled with Muse Cell Cycle Reagent for $30 \mathrm{~min}$ at room temperature and analyzed in a Cytoflex Flow Cytometer. The percentage of cells in stages G0/G1 $(2 \mathrm{~N}), \mathrm{S}(2 \mathrm{~N}-4 \mathrm{~N})$ and G2/M (4N) was determined as previously described (17).

Measurement of ROS level and mitochondrial membrane potential. To measure the ROS level, cells were stained for 30 min at $37^{\circ} \mathrm{C}$ with the probe $2^{\prime}, 7^{\prime}$-dichlorofluorescin diacetate (DCFDA; $20 \mu \mathrm{M}$ ) according to the manufacturers' instructions and the fluorescence was quantified in a Cytoflex Flow Cytometer. For maximal ROS inhibition, cells were treated for $30 \mathrm{~min}$ at $37^{\circ} \mathrm{C}$ with $5 \mathrm{mM}$ NAC prior to staining with DCFDA.
To detect changes in the mitochondrial membrane potential upon treatment with peptides, cells were stained with JC-1 $(1 \mathrm{mg} / \mathrm{ml})$ for $20 \mathrm{~min}$ at $37^{\circ} \mathrm{C}$. Fluorescence was measured in a Cytoflex flow cytometer. In normal cells, JC-1 emits red fluorescence $(590 \mathrm{~nm})$ and upon dissipation of the mitochondrial membrane potential, its emission changes to green fluorescence $(529 \mathrm{~nm})(18)$. The percentage of depolarized cells is indicated by the decrease in red fluorescence.

Peptide imaging by confocal microscopy. PC3, SKOV3 and T47D cells (1-2X10 cells $/ \mathrm{ml})$ were seeded into 4 -well chamber slides (Sigma-Aldrich; Merck KGaA) and kept in culture for $24 \mathrm{~h}$ in $\mathrm{CO}_{2}$ incubator. Then, cells were treated with biotinylated peptides at the indicated concentrations, for 5-10 min at $37^{\circ} \mathrm{C}$. Subsequently, cells were fixed with methanol for $10 \mathrm{~min}$ at $-20^{\circ} \mathrm{C}$, blocked with $5 \mathrm{mg} / \mathrm{ml} \mathrm{BSA}$ at room temperature for $1 \mathrm{~h}$, and permeabilized $(0.2 \%$ Triton $\mathrm{X}-100)$ for $60 \mathrm{~min}$ at room temperature. For nucleus staining, 300 nM DAPI solution was added for $5 \mathrm{~min}$ at room temperature. For peptide staining, cells were incubated with $5 \mu \mathrm{g} / \mathrm{ml}$ fluorescein-conjugated streptavidin for $30 \mathrm{~min}$ at room temperature. After washing with PBS containing $0.2 \%$ Triton X-100, the chambers were drained, coverslips were glued onto them with Mowiol (Sigma-Aldrich; Merck KGaA) and cells were kept in the dark for $24 \mathrm{~h}$. Cell imaging was performed using Leica-SP5 confocal microscope (Leica Microsystems, Inc.).

Measurement of peptide binding by ELISA. Microtiter plate wells were coated overnight at $4^{\circ} \mathrm{C}$ with BSA, C3, C9 or mortalin (all at $5 \mu \mathrm{g} / \mathrm{ml}$ ) in PBS. Wells were washed 3 times with PBS-T (0.05\% Twin) and blocked with $1 \%$ BSA for $1 \mathrm{~h}$ at room temperature. Subsequently, biotinylated peptides were added at 0.5 or $2.5 \mu \mathrm{g} / \mathrm{ml}$ to the wells for $1 \mathrm{~h}$ at room temperature. After washing, peroxidase-conjugated streptavidin was diluted in PBS according to the manufacturers' instructions and was added to the wells and incubated for $1 \mathrm{~h}$ at room temperature in the dark. Then, TMB One Component HRP Microwell Substrate was added and absorbance was read at $605 \mathrm{~nm}$ (450 nm if a stop solution was added) in a microplate reader.

CDC assay. Malignant B-cells in HBSS (5x105/100 $\mu \mathrm{l})$ were treated with Rituximab antibody against CD20 (RTX; $2 \mu \mathrm{g} / \mathrm{ml})$ for $30 \mathrm{~min}$ on ice. Next, $50 \%$ NHS was added for $60 \mathrm{~min}$ at $37^{\circ} \mathrm{C}$ in a shaking water bath. Cells treated with NHS without antibody served as negative controls. Cell death was measured either by trypan blue inclusion under a light microscope or by determining PI staining using flow cytometry. Percentage of cell death was calculated as described above.

Quantification of C3, C5b-9, CD20 and membrane complement regulators. Ramos cells were treated with RTX $(1.5 \mu \mathrm{g} / \mathrm{ml})$ for $30 \mathrm{~min}$ at $4^{\circ} \mathrm{C}$. Cells were then mixed with $50 \%$ NHS and further incubated for $10 \mathrm{~min}$ at $37^{\circ} \mathrm{C}$. To quantify bound $\mathrm{C} 3$, cells were treated with a goat anti-C3 antibody $(1: 1,000)$, followed by FITC-conjugated rabbit anti-goat IgG antibody (1:200). To quantify deposited C5b-9 (MAC), cells were labeled with a mouse anti-C5b-9 aE11 antibody (1:50), followed by FITC-conjugated goat anti-mouse IgG antibody (1:50). Cells were incubated with each antibody for $30 \mathrm{~min}$ on ice. 
To measure CD20 expression, Ramos cells labeled with $2 \mu \mathrm{g} / \mathrm{ml} \mathrm{RTX}$ for $30 \mathrm{~min}$ at $4^{\circ} \mathrm{C}$ were stained with Alexa-fluor 488-conjugated anti-human IgG antibody for $1 \mathrm{~h}$ on ice (1:500). To quantify the membrane complement regulators, cells were treated with mouse anti-CD46, anti-CD55 or anti-CD59 antibodies for 30 min at $4^{\circ} \mathrm{C}(1: 50)$ and then with FITC-conjugated secondary antibodies for $30 \mathrm{~min}$ at $4^{\circ} \mathrm{C}(1: 100)$. The labeled cells were analyzed by flow cytometry and the mean fluorescence intensity (MFI) was determined with CytExpert software v2.0 (Beckman Coulter).

Transient transfection by electroporation. $\mathrm{K} 562$ cells $\left(2.5 \times 10^{6}\right)$ were mixed in an electroporation cuvette (Cell Projects) with mortalin siRNA (500 pmol) or a nonspecific siRNA as control for $10 \mathrm{~min}$ at room temperature. Next, cells were electroporated with a BTX ECM 830 Electro Square Porator (225V, $14 \mathrm{msec}$ ), mixed with culture medium and cultured for $48 \mathrm{~h}$ at $37^{\circ} \mathrm{C}$. To validate siRNA insertion and transfection efficiency, transfected cells $\left(0.5 \times 10^{6}\right)$ were lysed with SDS-PAGE sample buffer, loaded on the gels and proteins were separated by 4-10\% gradient SDS-PAGE. Proteins were transferred onto nitrocellulose membranes. Membranes were blocked with 5\% skimmed milk and were incubated with primary antibodies against actin and mortalin for $1 \mathrm{~h}$ at room temperature (1:500). Membranes were incubated with peroxidase-conjugated secondary antibody for $1 \mathrm{~h}$ at room temperature $(1: 10,000$; Jackson ImmunoResearch Laboratories, Inc.). Bands were detected using Super-Signal West Pico Chemiluminescent Substrate (Pierce; Thermo Fisher Scientific, Inc.) and exposed to Super RX film (Fujifilm Wako Pure Chemical Corporation). Relative expression level of mortalin was normalized to actin using ImageJ v1.4 software (National Institutes of Health).

Statistical analysis. Student's paired t-test was used to compare two groups. Two-way ANOVA was performed to compare two groups: a tested reagent and the interaction between them. GraphPad Prism software v8 (GraphPad Software, Inc.) was used for statistical analysis. Data were expressed as the means \pm standard deviation. $\mathrm{P}<0.05$ was considered to indicate a statistically significant difference.

\section{Results}

Mortalin-derived peptides are cytotoxic. Mortalin is an essential housekeeping gene and cell protector from many toxic moieties $(3,12)$. Its concentration is elevated in cancer cells, suggesting that blocking mortalin protective activities may be an effective anti-cancer strategy. In the present study, the efficacy of mortalin mimetic peptides as inducers of cancer cell death was evaluated. Six mortalin mimetic peptides predicted by computational analysis to be exposed on the surface of human mortalin and a scrambled control peptide were synthesized. Initial analysis with Ramos cells clearly indicated that adding a TAT sequence at the C-terminal of the peptides significantly increased peptide cytotoxicity (Fig. S1). Therefore, all peptides described in the present study possessed a C-terminal TAT. A dose-response analysis of the cytotoxicity of the six peptides over $24 \mathrm{~h}$ in Ramos, Raji and Z-138 lymphoma cells is presented in Fig. 1A-C. Based on these titration curves, the lethal dose (LD50) of the peptides was calculated (Table SI). The two most potent peptides, Mot-P2 (LD50, 26-30 $\mu \mathrm{M}$ ) and Mot-P7 (LD50, 40-63 $\mu \mathrm{M}$ ), were chosen for further experiments. Subsequently, the toxicity of the peptides was tested on B-CLL cells from patients and on PBMC from healthy donors. Mot-P2 and Mot-P7 (both at $50 \mu \mathrm{M}$ ) were demonstrated to be toxic for both B-CLL cells and PBMC; however, PBMC were less sensitive (Fig. 1D). Mot-P2 caused $77.0 \pm 9.4 \%$ and $42.7 \pm 27.4 \%$ cell death in B-CLL and PBMC cells, respectively $(\mathrm{P}=0.03)$. Furthermore, Mot-P7 caused $47.8 \pm 15.4 \%$ and $21.5 \pm 14.3 \%$ cell death in B-CLL and PBMC cells, respectively $(\mathrm{P}=0.03)$. Primary B-CLL cells and $\mathrm{B}$-cell leukemia/lymphoma established cell lines could express a similar sensitivity to toxicity from Mot-P2 and Mot-P7. At the concentration of $50 \mu \mathrm{M}$, cell death of Ramos, Raji and Z138 cells by Mot-P2 was $90-100 \%$, and by Mot-P7, 50-85\% (Fig. 1A-C). Under the same conditions, $75 \%$ of primary CLL cells were lysed by Mot-P2 and $\sim 45 \%$ by Mot-P7 (Fig. 1D). The peptides were also tested on the three human carcinoma cell lines PC3 (human prostate cancer); T47D (breast cancer) and SKOV3 (ovarian carcinoma). The results demonstrated that cell death was almost maximal after $4 \mathrm{~h}$ treatment. As presented in Fig. 1E, Mot-P2 $(50 \mu \mathrm{M})$ and Mot-P7 $(100 \mu \mathrm{M})$ were toxic for all carcinoma cell lines.

Peptide uptake and intracellular distribution in carcinoma cells. The intracellular distribution of biotin-labeled Mot-P2 and Mot-P7 was studied in carcinoma cells by confocal microscopy. This could not be performed on lymphoma cells because of their size and morphology. Cells were incubated with the peptides $\left(5 \mathrm{~min}\right.$ at $\left.37^{\circ} \mathrm{C}\right)$ and labeled with Streptavidin-FITC as aforementioned. Mot-P2 and Mot-P7 were rapidly taken up by PC-3, SKOV-3 and T47D cells (Fig. S2). The results demonstrated that Mot-P2 was distributed throughout the cytoplasm and nucleus, which was similar to a previous study reporting nuclear accumulation of the TAT protein basic domain (19). The distribution of Mot-P7 was slightly different, with more peptides localized at the plasma membrane and less in the cytoplasm and nucleus. The kinetics of the peptides' internalization process was followed up to $15 \mathrm{~min}$. However, with increasing time, the data became less informative, as an increasing percentage of the cells started undergoing cell death and a nuclear/pancytoplasmic/membrane distribution of the peptides became apparent.

Effects of Mot-P2 and Mot-P7 on plasma membrane. Since Mot-P2 and Mot-P7 are highly cytotoxic, analysis was performed before cell death got too extensive. A kinetic analysis of Mot-P2 and Mot-P7 cytotoxicity on Ramos cells was performed with a relatively higher concentration of Mot-P7 (100 $\mu \mathrm{M} \mathrm{P} 7$ and $25 \mu \mathrm{M} \mathrm{P} 2$, in order to reach a similar level of cell death). Almost maximal cell death was achieved by both peptides within $30 \mathrm{~min}$, although Mot-P2 acted slightly faster than Mot-P7 (Fig. 2A). Plasma membrane perforation was also confirmed by LDH leakage, demonstrating a higher toxicity for Mot-P2 (Fig. 2B). Various cell death processes are known to disturb plasma membrane asymmetry and cause flip-flopping of phosphatidylserine (PS) from the inner to the outer leaflet of the plasma membrane $(20,21)$. Externalized PS was therefore quantified by binding with Annexin V. Ramos cells were treated with Mot-P2 or Mot-P7 and labelled 
A

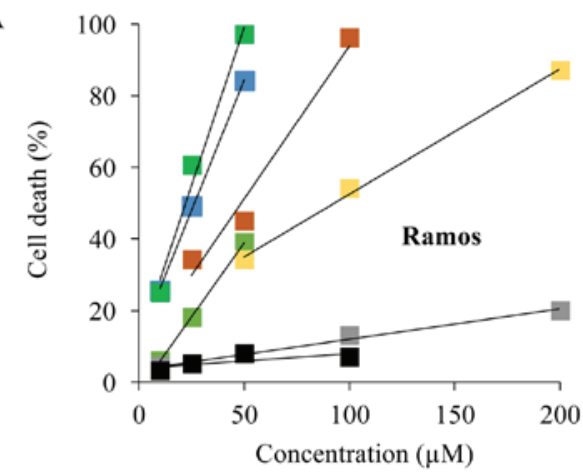

B

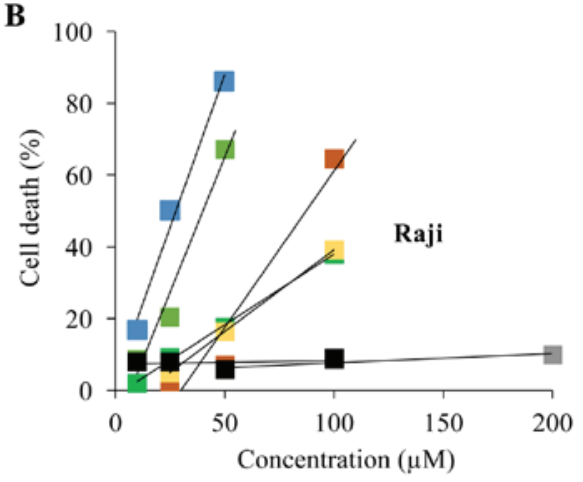

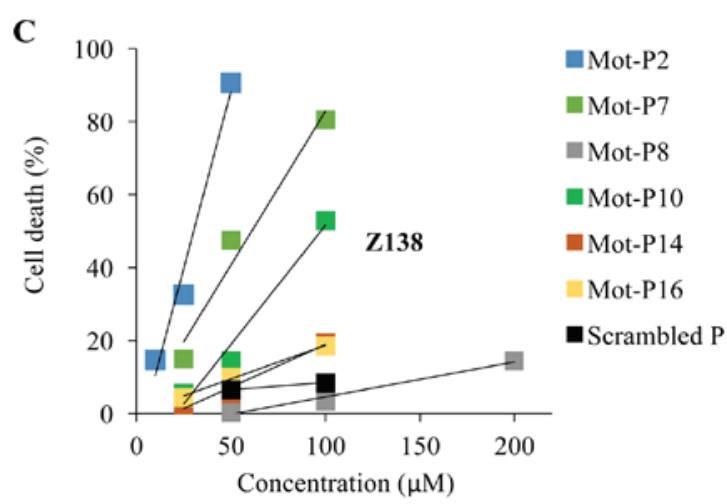
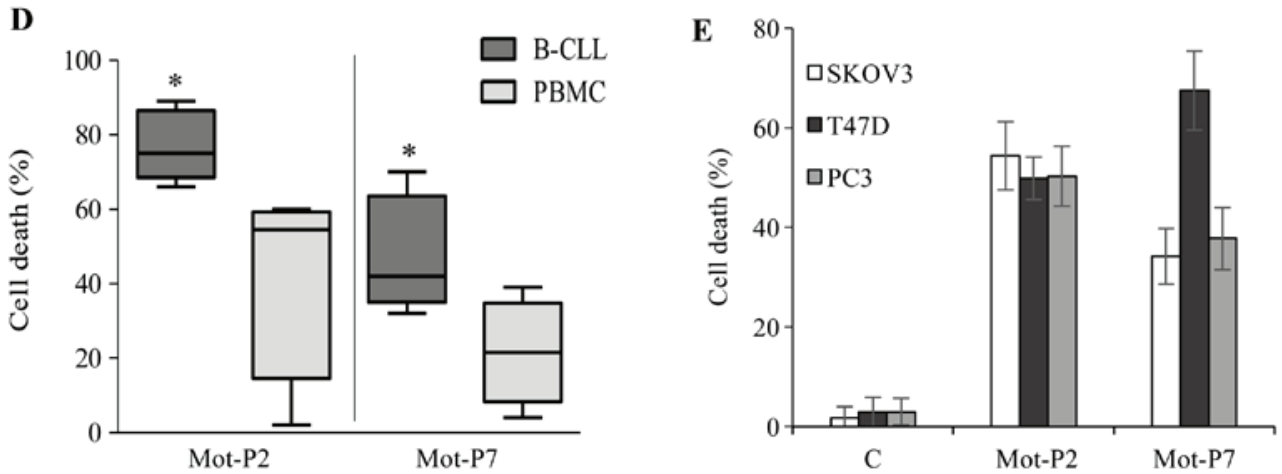

Figure 1. Cytotoxicity of mortalin mimetic peptides. (A) Ramos, (B) Raji and (C) Z138 lymphoma cells were incubated with the indicated concentrations of a TAT-linked mortalin peptide or scrambled peptide for $24 \mathrm{~h}$ at $37^{\circ} \mathrm{C}$. Cells were washed, stained with propidium iodide and analyzed by flow cytometry. Percentage of cell death was calculated. $n=3$. (D) PBMC isolated from the blood of 5 patients with B-CLL and 4 healthy donors were treated in triplicate with $50 \mu \mathrm{M}$ Mot-P2 or Mot-P7 for $24 \mathrm{~h}$ at $37^{\circ} \mathrm{C}$. Cells were washed, labeled with DAPI and analyzed by flow cytometry. Percentage of cell death was calculated ${ }^{*} \mathrm{P}<0.05$, B-CLL vs. PBMC. (E) Carcinoma cells (PC3, SKOV3 and T47D) were incubated for $4 \mathrm{~h}$ at $37^{\circ} \mathrm{C}$ with $50 \mu \mathrm{M}$ Mot-P2 or $100 \mu \mathrm{M}$ Mot-P7 or DMSO as control. Cells were washed and percentage of cell death was determined by trypan blue inclusion. $\mathrm{n}=3$. TAT, transactivator of transcription; B-CLL, B-cell chronic lymphocytic leukemia; PBMC, Peripheral blood mononuclear; C, control.

with annexin-V-FITC and PI to detect changes in plasma membrane asymmetry and permeability. Following Mot-P2 treatment, all damaged cells were positive for Annexin $\mathrm{V}$ and PI (Fig. 2C and D). PS externalization and PI entry occurred therefore in all damaged cells. Conversely, Mot-P7-treated cells exhibited two distinct damaged cell populations: one with intact plasma membrane (PI-negative) and labeled with annexin-V-FITC and one labeled both by Annexin V and PI (Fig. 2C and D). Interestingly, at a lower Mot-P7 concentration, more cells were single Annexin V-positive, whereas, at a higher Mot-P7 concentration, more cells were double Annexin V- and PI-positive. These results suggested that the mechanisms of action of Mot-P2 and Mot-P7 are distinct. Caspases that mediate apoptotic cell death activate PS exter- nalization (20). QVD is a pan-caspase inhibitor (22). Prior to exposure to peptides, Ramos cells were treated with QVD or with DMSO as control. Subsequently, cells were treated with Mot-P2 or Mot-P7. In addition, cells were also treated with staurosporine, which is an apoptosis inducer (21). As presented in Fig. 3A, pre-treatment with QVD inhibited the death (i.e., double labeling) of staurosporine-treated cells. However, QVD had no effect on cell death following Mot-P2 or Mot-P7. Therefore, unlike staurosporine, the peptides activate a caspase-independent, probably necrotic cell death.

Due to the much higher calcium ion concentration outside the cells compared with inside cells, pore formation can lead to a rapid influx of calcium ions into the cytoplasm, calcium toxicity, and cell death (23). To examine the impact of calcium influx 
A

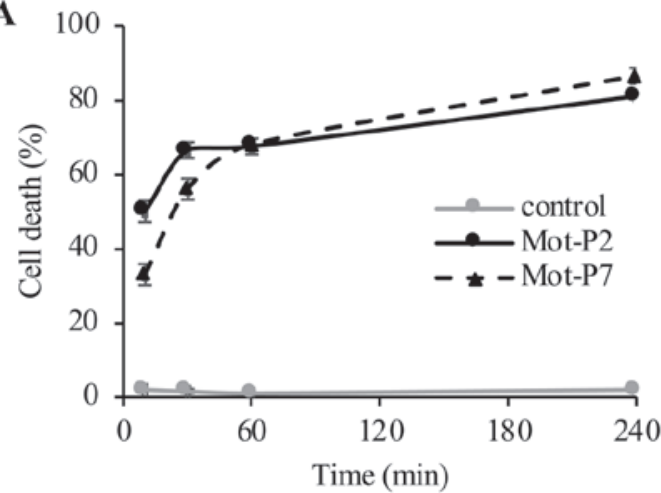

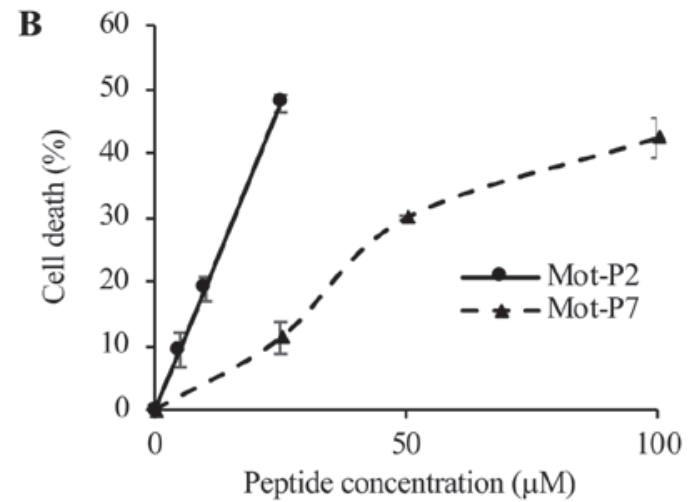
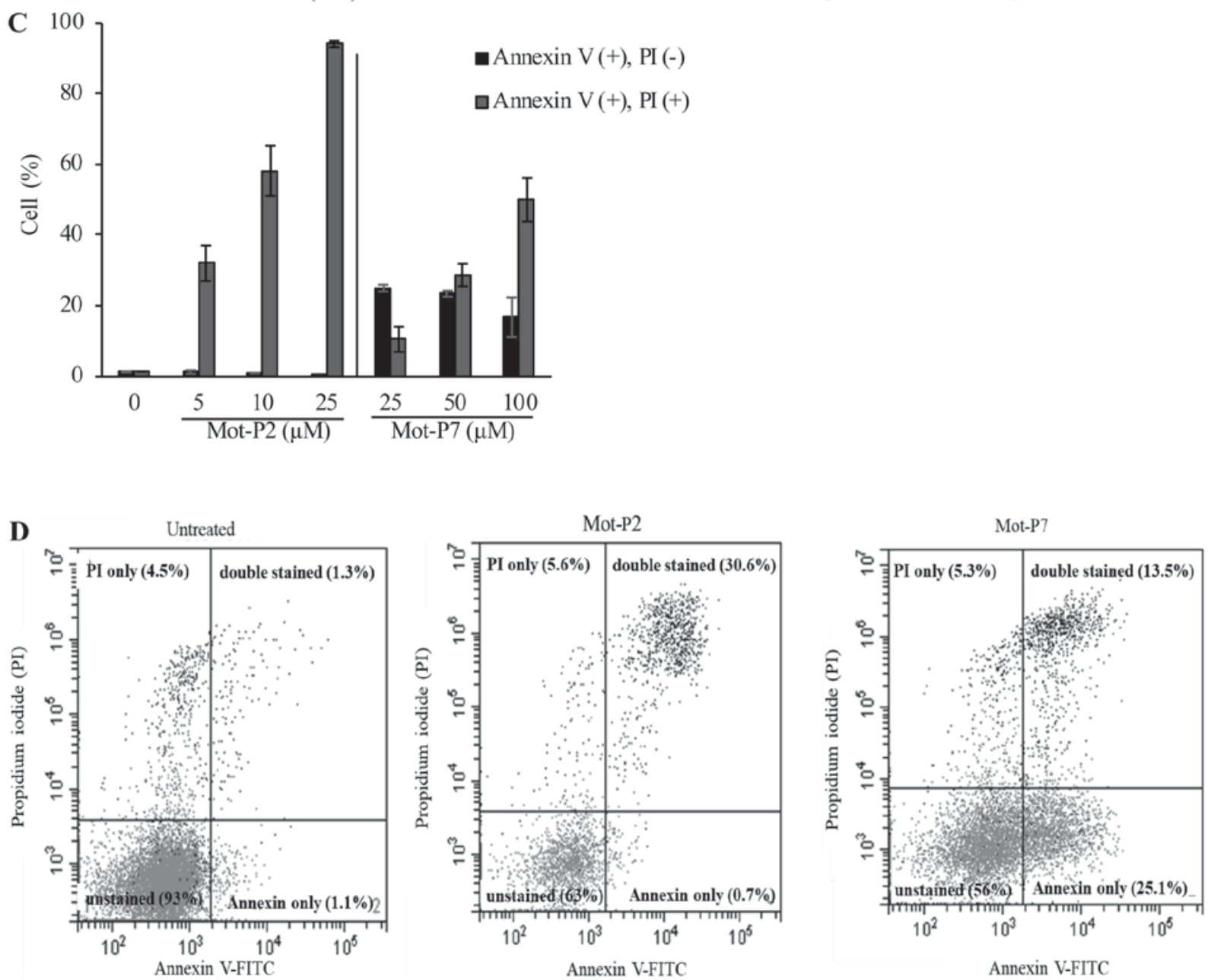

Figure 2. Mot-P2 and Mot-P7 induced a rapid loss of plasma membrane integrity and PS externalization. (A) Ramos cells, assessed in triplicates, were incubated with $25 \mu \mathrm{M}$ Mot-P2 or $100 \mu \mathrm{M}$ Mot-P7 for 10,30, $60 \mathrm{~min}$ or $4 \mathrm{~h}$ at $37^{\circ} \mathrm{C}$. Cell death (\%) was determined by PI exclusion. $\mathrm{n}=4$. (B) To measure LDH leakage, Ramos cells $\left(5 \times 10^{4}\right)$ were treated with the indicated doses of Mot-P2 and Mot-P7 for $30 \mathrm{~min}$ at $37^{\circ} \mathrm{C}$. Percentage of cell death (LDH release) was measured with the CytoTox-ONE Reagent. (C) Ramos cells were treated for $30 \mathrm{~min}$ at $37^{\circ} \mathrm{C}$ with the indicated concentrations of peptides Mot-P2 or Mot-P7. $\mathrm{n}=3$. PS externalization and cell membrane integrity were determined by flow cytometry after staining with Annexin V-FITC and PI, respectively. (D) Representative dot plots illustrating the effect of $5 \mu \mathrm{M}$ Mot-P2 and $25 \mu \mathrm{M}$ Mot-P7 on Annexin V-FITC/PI staining. $\mathrm{n}=3$. PI, propidium iodide; PS, phosphatidylserine.

on peptide cytotoxicity, extracellular calcium was chelated with EGTA $(10 \mathrm{mM})$ and supplemented with $\mathrm{MgCl}_{2}(2.5 \mathrm{mM}$; Mg-EGTA) prior to peptide treatment. The results demonstrated that the toxic effect of Mot-P7, but not that of Mot-P2, was partially inhibited by extracellular calcium ablation (Fig. 3B).

Membrane cholesterol is known to modulate the interaction of some membranolytic peptides and proteins with the plasma membrane and affect therefore their cytotoxicity (24-26). To determine whether cholesterol serve a role in Mot-P2 and Mot-P7 cytotoxicity, the effect of two cholesterol membrane blocking or depleting agents, methyl- $\beta$-cyclodextrin (M $\beta C D)$ and filipin III, respectively, on cell death was tested. As demonstrated in Fig. 3C and D, both cholesterol depletion and inhibition led to a significant increase in Mot-P2 and Mot-P7 cytotoxicity in Ramos cells, suggesting that plasma membrane cholesterol may limit Mot-P2 and Mot-P7 cytotoxicity. 

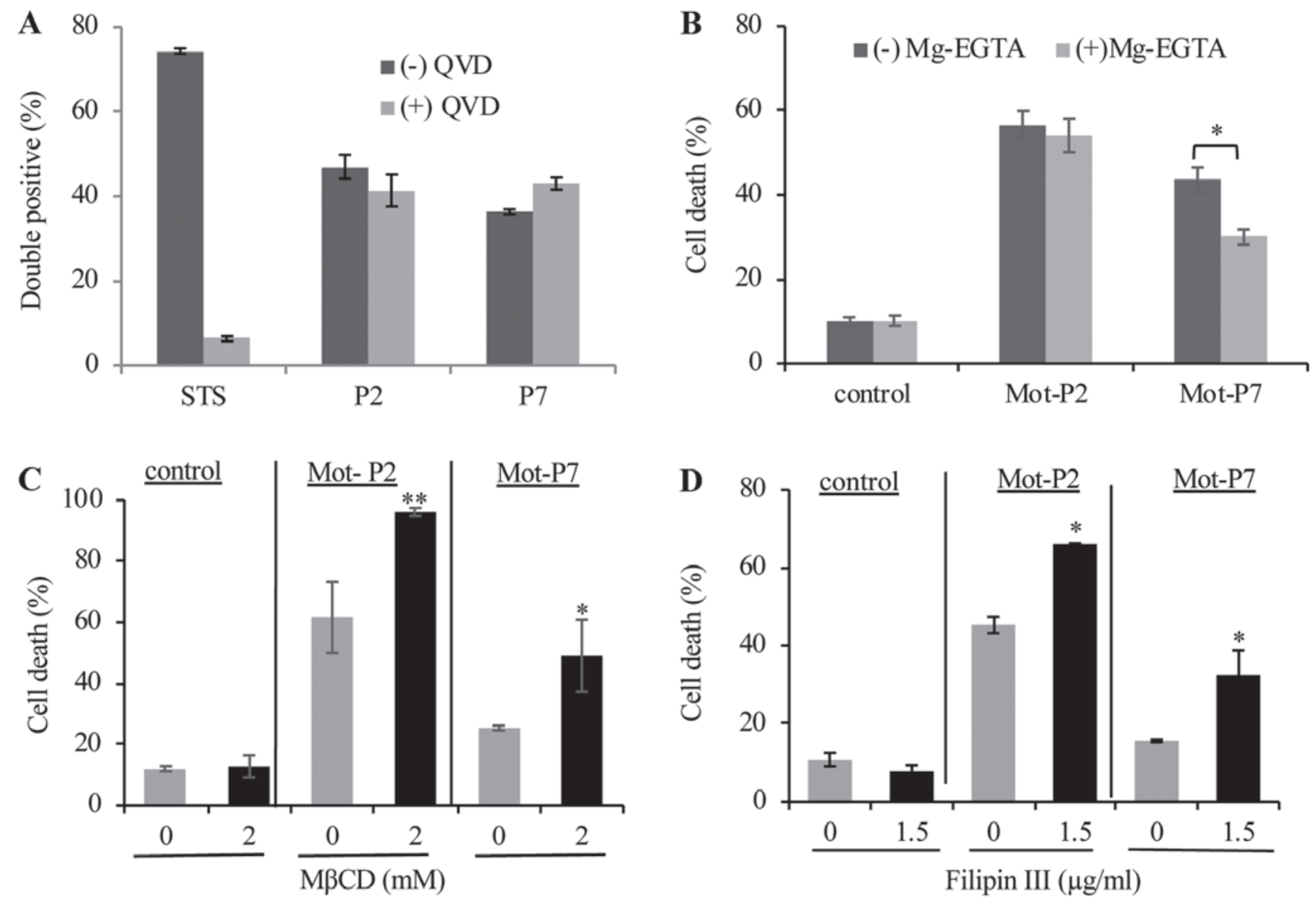

Figure 3. Role of calcium and cholesterol in peptide cytotoxicity. (A) Ramos cells were pretreated with $50 \mu \mathrm{M}$ QVD or DMSO as control for $1 \mathrm{~h}$ at $37^{\circ} \mathrm{C}$. Cells were then treated with $20 \mu \mathrm{M}$ Mot-P2 or $75 \mu \mathrm{M}$ Mot-P7 or $2 \mu \mathrm{M}$ of STS as a positive control for $4 \mathrm{~h}$ at $37^{\circ} \mathrm{C}$. PS externalization and cell membrane integrity were determined by flow cytometry after staining with Annexin V-FITC and PI, respectively. Percentage of double-positive cells is presented. (B) Ramos cells were pretreated for $30 \mathrm{~min}$ at $37^{\circ} \mathrm{C}$ with $\mathrm{Mg}$-EGTA for calcium chelation. Toxic doses of Mot-P2 or Mot-P7 $(25 \mu \mathrm{M}$ or $50 \mu \mathrm{M}$, respectively) were added for additional $30 \mathrm{~min}$. Cells were washed, labeled with PI and cell death was analyzed by flow cytometry. Peptide-treated. $n=3$. "P<0.05 vs. untreated cells, $\mathrm{n}=4$. (C and D) Ramos cells were pretreated for $30 \mathrm{~min}$ at $37^{\circ} \mathrm{C}$ with (C) 0 or $2 \mathrm{mM} \mathrm{M} \beta \mathrm{CD}$ or (D) with 0 or $1.5 \mu \mathrm{g} / \mathrm{ml}$ Filipin III (C) for membrane cholesterol depletion or inhibition, respectively. Next, cells were treated for $30 \mathrm{~min}$ at $37^{\circ} \mathrm{C}$ with $25 \mu \mathrm{M}$ Mot-P2 or $50 \mu \mathrm{M}$ Mot-P7. Cells were washed, labeled with PI and analyzed by flow cytometry. $n=3,{ }^{*} \mathrm{P}<0.05$ and ${ }^{* *} \mathrm{P}<0.01$ vs. untreated cells. $\mathrm{M} \beta \mathrm{CD}$, methyl- $\beta$-cyclodextrin; STS, staurosporine; PS, phosphatidylserine.

Effects of Mot-P2 and Mot-P7 on the mitochondria. The observation of a membrane damaging effect by Mot-P2 and Mot-P7 suggested that both peptides may partially induce cell death by causing mitochondrial toxicity. The effect of peptides on the mitochondrial membrane potential was examined by cell staining with JC-1, which is a cationic dye that accumulates in the mitochondria of healthy cells. As presented in Fig. 4A, Mot-P2 and Mot-P7 both dissipated the mitochondrial membrane potential in Ramos cells; however, the effect was higher with Mot-P2.

After mitochondrial damage, ATP production may be decreased to a level causing or amplifying cell death. The effect of Mot-P2 and Mot-P7 on the ATP level in Ramos, SKOV3, T47D and PC3 cells was subsequently evaluated. Compared with the scrambled peptide, both Mot-P2 and Mot-P7 caused, within 30 min, a dramatic dose-dependent drop in the cellular ATP level, in the four cell lines tested (Fig. 4B-E). Furthermore, a Mot-P7 concentration 4-8 times higher than Mot-P2 was required to cause a 50\% drop in ATP level. In addition, Mot-P2 and Mot-P7 caused, within 10 min at $37^{\circ} \mathrm{C}$, concomitantly plasma membrane pore formation ( $\mathrm{LDH}$ release) and mitochondrial damage (ATP drop; Fig. S3).
Besides inhibition of ATP synthesis, peptide-induced mitochondrial stress may result in overproduction of ROS. Mortalin is a mitochondrial chaperone involved in cell protection from ROS (27). The effect of Mot-P2 and Mot-P7 on ROS production was therefore evaluated using the ROS-sensitive fluorescent dye DCFDA. The results demonstrated that Ramos cell treatment with Mot-P2 or Mot-P7 significantly increased ROS level (Fig. 5A). To investigate whether ROS contributes to cell death, cells were pre-incubated with NAC, which is a ROS scavenger (28), prior to peptide treatment. The results demonstrated that Mot-P2-induced cell death was not affected by ROS inhibition (Fig. 5B). Conversely, Mot-P7-induced cell death was inhibited by NAC (Fig. 5B), suggesting a difference in the mode of action of the two peptides.

Effect of Mot-P2 and Mot-P7 at non-toxic concentration on cell proliferation. The effect of the peptides at low, non-toxic, concentrations on cell proliferation was investigated. Treatment of Ramos cells with $5 \mu \mathrm{M}$ Mot-P2 or $25 \mu \mathrm{M}$ Mot-P7, moderately, but significantly, reduced the rate of cell proliferation in the absence of cell death (Fig. S4). The ability of Mot-P2 and Mot-P7 to alter cell cycle progression was therefore examined. 

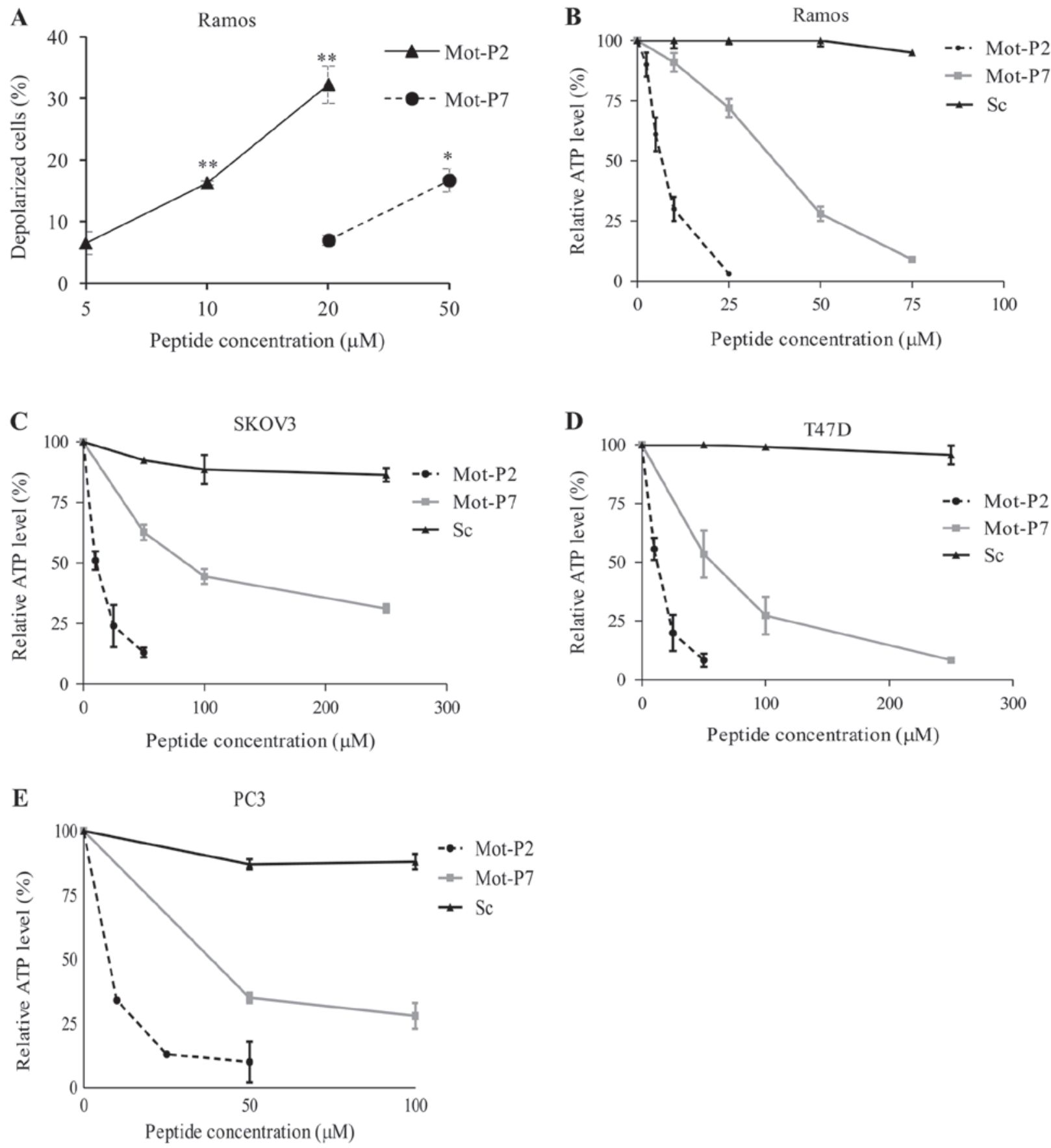

Figure 4. Mot-P2 and Mot-P7 induced mitochondrial membrane depolarization and ATP loss. (A) Ramos cells were incubated with the indicated doses of Mot-P2 or Mot-P7 or with DMSO for $30 \mathrm{~min}$ at $37^{\circ} \mathrm{C}$ and washed. Next, cells were stained with JC-1 and the percentage of cells with depolarized mitochondrial inner membrane (reduced red fluorescence) was calculated. $n=3$. "P<0.05 and ${ }^{* *} \mathrm{P}<0.01$ vs DMSO-treated cells. (B-E) (B) Ramos, (C) SKOV3, (D) T47D and (E) PC3 cells were seeded in wells of 96-well plates and treated with the indicated concentrations of peptide Mot-P2, Mot-P7 or Sc peptide for 30 min at $37^{\circ} \mathrm{C}$. Cellular ATP level was quantified with the CellTiter-Glo reagent and expressed as percentage of ATP level, relative to the ATP level in control DMSO-treated cells. $n=3$. Sc, scramble.

Ramos cells were grown with a subtoxic dose of Mot-P2 or Mot-P7 for $36 \mathrm{~h}$; then the distribution of the cells among the cell cycle division phases was analyzed. Treatment with Mot-P2 and Mot-P7, but not scrambled peptide, reduced the percentage of cells in G0/G1 and increased the percentage of cells in $\mathrm{G} 2 / \mathrm{M}$ (Fig. 5C). This suggests that the peptides cause a cell cycle arrest in the $\mathrm{G} 2 / \mathrm{M}$ phase.

Intracellular mortalin is a target of Mot-P2 and Mot-P7. Mortalin protects cells from various insults by binding to its numerous target proteins. The mimetic mortalin peptides were hypothesized to interfere with some of these interactions and to potentially reverse cell protection by mortalin. Mortalin downregulation was performed in K562 cells. Mortalin was downregulated in K562 cells with a specific siRNA as previously described (13). Cells were transfected with mortalin siRNA or a control non-specific siRNA and grown for $48 \mathrm{~h}$ prior to peptide treatment. The results demonstrated that transfection induced a decrease in mortalin expression (Fig. 5D). In addition, cell death following treatment with Mot-P2 and 

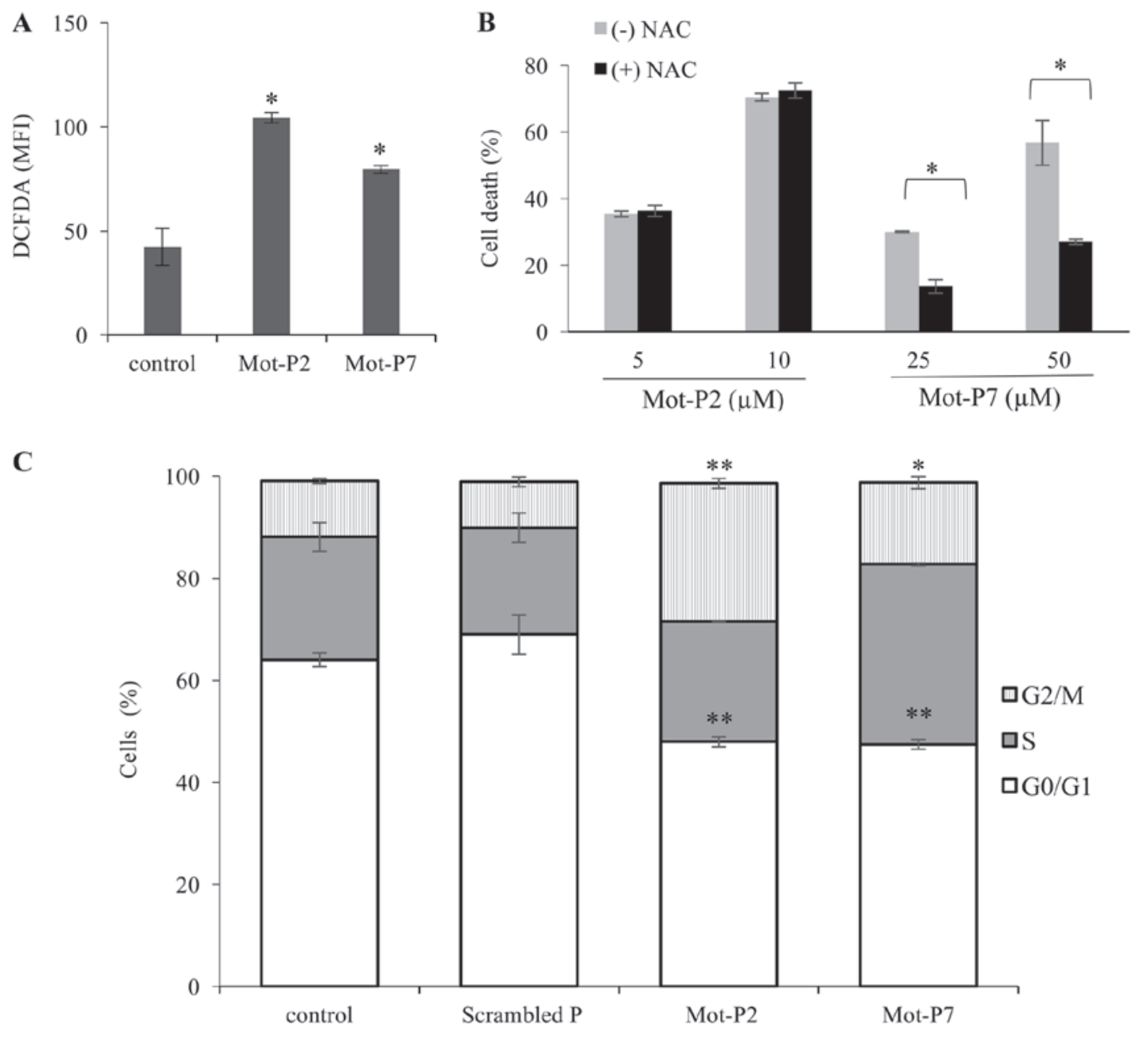

D

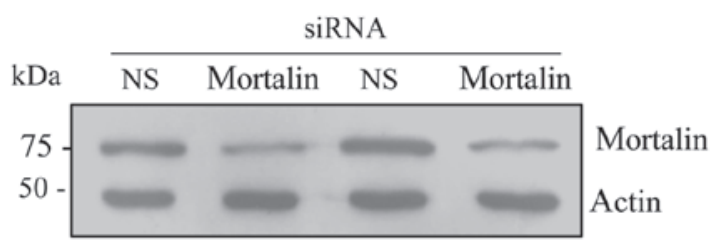

$\mathbf{E}$

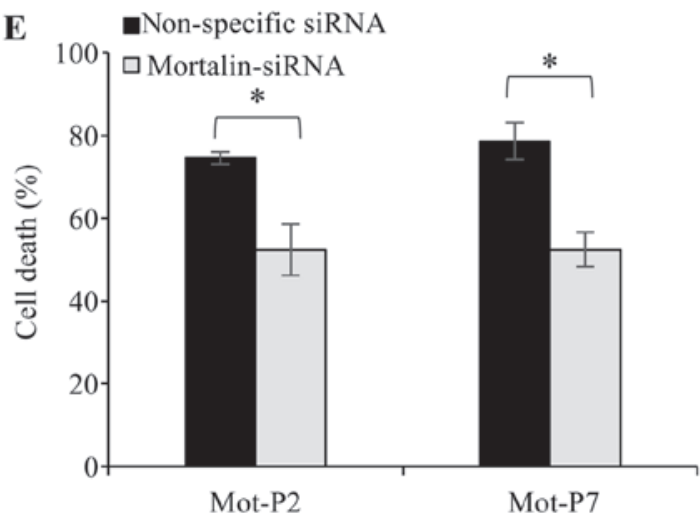

Figure 5. Mot-P2 and Mot-P7 activities. (A) ROS are involved in Mot-P7- but not Mot-P2-induced cell death. (A) Ramos cells were stained with $20 \mu \mathrm{M}$ DCFDA for $30 \mathrm{~min}$ at $37^{\circ} \mathrm{C}$ in the dark. Next, cells were treated with $10 \mu \mathrm{M}$ Mot-P2 or $50 \mu \mathrm{M}$ Mot-P7 for $1 \mathrm{~h}$ at $37^{\circ} \mathrm{C}$. Mean fluorescence intensity of DCFDA was analyzed by flow cytometry. $n=3 .{ }^{*} \mathrm{P}<0.05$ vs. DMSO-treated cells. (B) Ramos cells were pretreated with $5 \mathrm{mM}$ NAC for 30 min at $37^{\circ} \mathrm{C}$. Next, cells were treated with the indicated concentrations of Mot-P2 or Mot-P7 for $1 \mathrm{~h}$ at $37^{\circ} \mathrm{C}$. Cells were washed, labeled with PI and analyzed by flow cytometry. ${ }^{*} \mathrm{P}<0.05 \mathrm{vs}$. cells not treated with NAC. $\mathrm{n}=4$. (C) Sub-toxic Mot-P2 and Mot-P7 induced cell cycle arrest. Ramos cells were treated with a sub-toxic dose of Mot-P2, Mot-P7 or a scrambled peptide $\left(5,15\right.$ or $15 \mu \mathrm{M}$, respectively) or DMSO (control) for $36 \mathrm{~h}$ at $37^{\circ} \mathrm{C}$. Next, cells were fixed with $70 \%$ cold ethanol for $2 \mathrm{~h}$ and stained with PI. Distribution of cells among the various cell cycle stages was analyzed by flow cytometry. $\mathrm{n}=3,{ }^{*} \mathrm{P}<0.05$ and ${ }^{* *} \mathrm{P}<0.01$ vs. control cells. (D and E) Silencing of mortalin lowers peptide cytotoxicity. (D) K562 cells were transfected with mortalin siRNA or NS siRNA as a control. At $48 \mathrm{~h}$ post transfection, mortalin knockdown was verified by western blotting. (E) Transfected cells were seeded in wells of 96-well plates and treated with $10 \mu \mathrm{M}$ Mot-P2 or $75 \mu \mathrm{M}$ Mot-P7 for $1 \mathrm{~h}$ at $37^{\circ} \mathrm{C}$. The extent of cell death was measured by LDH release. $\mathrm{n}=3$. ${ }^{\prime} \mathrm{P}<0.05 \mathrm{vs}$. NS siRNA transfected cells. NAC, N-acetyl cysteine; DCFDA, 2,7'-dichlorofluorescin diacetate; PI, propidium iodide; NS, non specific; si, small interfering.

Mot-P7 was significantly decreased (Fig. 5E). These findings were confirmed in PC3 and T47D cells. The results demonstrated that mortalin downregulation in PC3 and T47D cells also partially decreased cell sensitivity to Mot-P2 and Mot-P7 (Fig. S5). These results suggested that Mot-P2 and Mot-P7 may partially induce cytotoxicity by binding either to mortalin 
or to a mortalin binder. Still, both peptides may also have an additional cytotoxic activity that could be independent of mortalin; however, this remains to be elucidated.

Combined effect of Mot-P2 and Mot-P7 with CDC. As previously described, mortalin protects cells from antibody-mediated CDC $(12,14)$, and mortalin inhibitors potentiate the cytotoxic action of complement (13). Since Mot-P2 and Mot-P7 can partially target their action to mortalin or mortalin-binders (Fig. 5E), it was anticipated that Mot-P2 and Mot-P7 would affect CDC. CDC was tested on Ramos cells coated with RTX antibodies and then treated with human complement. Based on an antibody titration assay (Fig. S6), the RTX concentration that activates complement on lymphoma cells and yields a low percentage cell death ( $30-40 \%)$ was determined. Next, Ramos cells were treated with Mot-P2 or Mot-P7 concentrations causing low-toxicity (25-35\% cell death) and with RTX and complement (NHS), also at a low-toxic concentration. The combined treatments with peptide and complement led to an additive cytotoxic effect (Fig. 6A). Thus, whereas Mot-P2 alone, Mot-P7 alone and NHS alone caused 28, 35 and $34 \%$ cell death, respectively, Mot-P2 + NHS and Mot-P7 + NHS induced 52 and $49 \%$ cell death, respectively. Combining either Mot-P2 or Mot-P7 with CDC may therefore result in increased cytotoxicity.

These peptides may enhance RTX-mediated CDC by enhancing the cell CD20 level, by enhancing the cell C3 and/or C5b-9 deposition levels and/or C5b-9 deposition by suppressing the expression level of the membrane complement regulators CD46, CD55 and CD59 and/or by lowering the protective capacity of mortalin. The results demonstrated that Mot-P2 and Mot-P7 had no effect on the amount of bound RTX, suggesting that the peptides did not modify CD20 expression level on the cells (Fig. S7). Subsequently, the impact of the peptides on C3 and C5b-9 deposition was analyzed. Ramos cells were treated with Mot-P2 or Mot-P7 and then with RTX and NHS. Treatment time with NHS was $10 \mathrm{~min}$, which corresponded to the peak time for C3 and C5b-9 depositions (29). Both Mot-P2 and Mot-P7 slightly decreased the extent of C3 deposition (Fig. 6B), and slightly enhanced the C5b-9 deposition level (Fig. 6C). Expression level analysis of the membrane complement regulatory proteins on peptide-treated and control cells demonstrated that Mot-P2 and Mot-P7 had no effect on CD46 and CD55, but slightly decreased the CD59 expression level (Fig. 6D). Consequently, the reduced expression of CD59 in peptide-treated cells may account for the elevated deposition of C5b-9. However, more deposited C5b-9 does not necessarily indicate higher cytotoxic activity. A significant proportion of the deposited C5b-9 is only peripherally attached to the cells and does not contribute to cytotoxicity (30). Unlike the fully inserted cytotoxic C5b-9, the peripherally attached C5b-9 is sensitive to trypsinization (29). To quantify the amount of the fully inserted C5b-9 on peptide-treated and control cells, Ramos cells were treated with Mot-P2 or Mot-P7 first, followed by RTX and NHS (10 min) and then with trypsin. As presented in Fig. 6C, trypsinization decreased the amount of deposited C5b-9, with no significant difference in the amount of trypsin-resistant C5b-9 between peptide-treated and control cells. These findings suggested that the Mot-P2 and Mot-P7-enhancing effect on CDC may not result from the observed reduced CD59 expression and enhanced C5b-9 deposition. To determine whether peptides could bind directly to intracellular mortalin and therefore affect its protective activity, the direct binding of biotin-labeled Mot-P2 or Mot-P7 to mortalin was tested by ELISA. Peptide binding to mortalin was compared with their binding to C3, C9 and BSA. The results demonstrated that, unlike a scrambled peptide, Mot-P2 bound strongly to mortalin (Fig. 6E and G). In addition, Mot-P7 demonstrated only a moderate yet significant binding to mortalin (Fig. 6F). Mot-P2 and Mot-P7 did not bind to C3 or C9.

\section{Discussion}

Because of its ubiquitous elevated expression in cancer cells and its suggested role in cell protection from toxic insults (10), mortalin has been considered as a potential target in cancer therapy. This hypothesis was supported by previous studies using the mortalin inhibitor MKT-077 (13,31). The present study hypothesized that mortalin mimetic peptides could interfere with the protective mechanisms of mortalin and might therefore be used as tumor therapeutic agents. Several peptides from the nucleotide-binding or the substrate-binding domains of mortalin were designed and a TAT sequence was added to their C-terminal to promote their cell penetration ability. Two peptides, Mot-P2 and Mot-P7, from the nucleotide-binding domain of mortalin, were demonstrated to be highly toxic to lymphoma and carcinoma cell lines and to primary CLL cells. However, these two peptides were significantly less toxic for healthy PBMC. The peptide cytotoxic efficiency at low micromolar concentrations was also attributed to the linked TAT. However, the lack of cytotoxicity of a TAT-linked scrambled peptide, as well as the lower toxicity of Mot-P8, suggested that cytotoxicity is peptide-dependent. This was further confirmed following mortalin knockdown, when cells became less sensitive to the peptides. In addition, at a non-toxic concentration, the two peptides interfered with cell cycle progression and induced a $\mathrm{G} 2 / \mathrm{M}$ arrest.

The low LD50 for Mot-P2 and Mot-P7 encouraged us to investigate their mode of action. The results identified several similarities and differences in their modes of action (Table I). The two peptides were highly cytotoxic and induced cell death within minutes after cell binding. Cell death was necrosis, as PI entered into and LDH leaked out of the affected cells, indicating plasma membrane damage. Within minutes, phosphatidylserine flipped to the extracellular surface of the plasma membrane, possibly after activating scramblase or by another mechanism (20). Loss of plasma membrane asymmetry was described first for apoptosis; however, it has also been demonstrated in cell development, injury, senescence and necrosis (21).

The present study demonstrated that Mot-P2 and Mot-P7 had different effects on plasma membrane. Whereas Mot-P2 activated concomitant PS externalization and PI entry, Mot-P7 activated PS externalization only in some cells and both PS externalization and PI entry in other cells. These findings suggested that Mot-P7 may activate PS externalization independent of plasma membrane perforation in some cells. This was supported by the observation that in the first 10-15 min, less LDH was released from Mot-P7-treated cells compared 
A
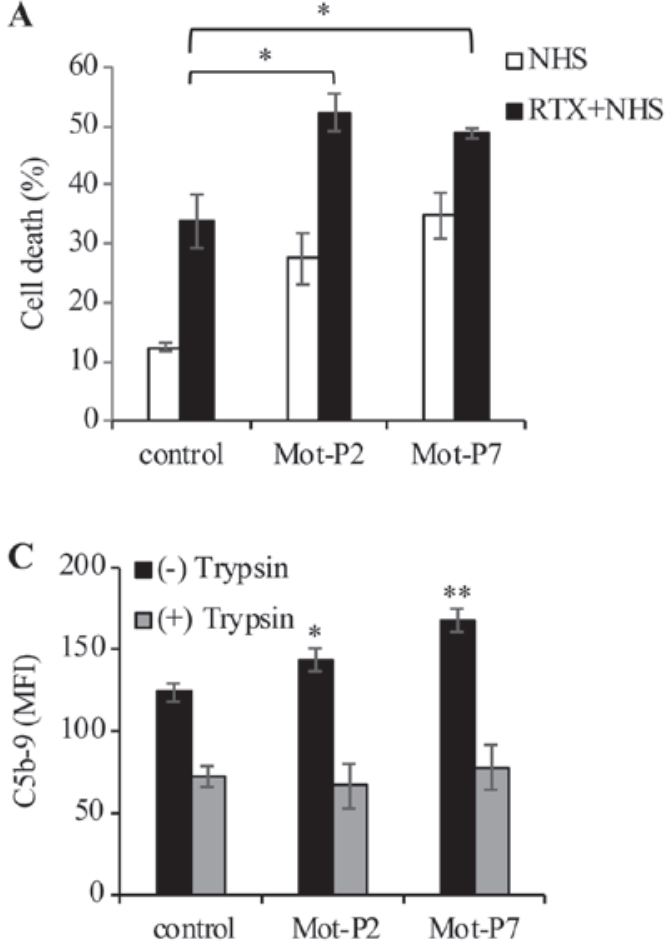

$\mathbf{E}$

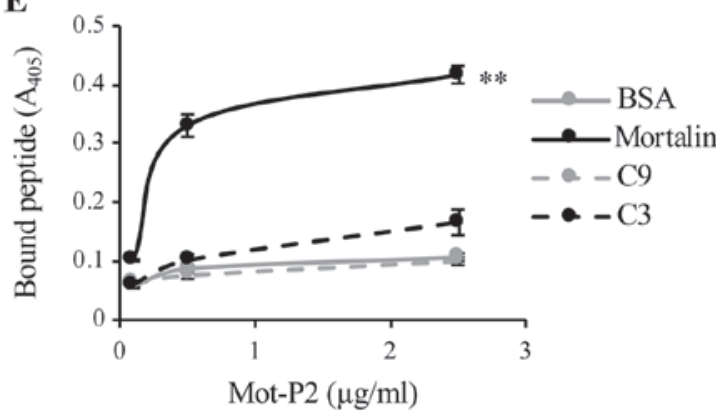

B
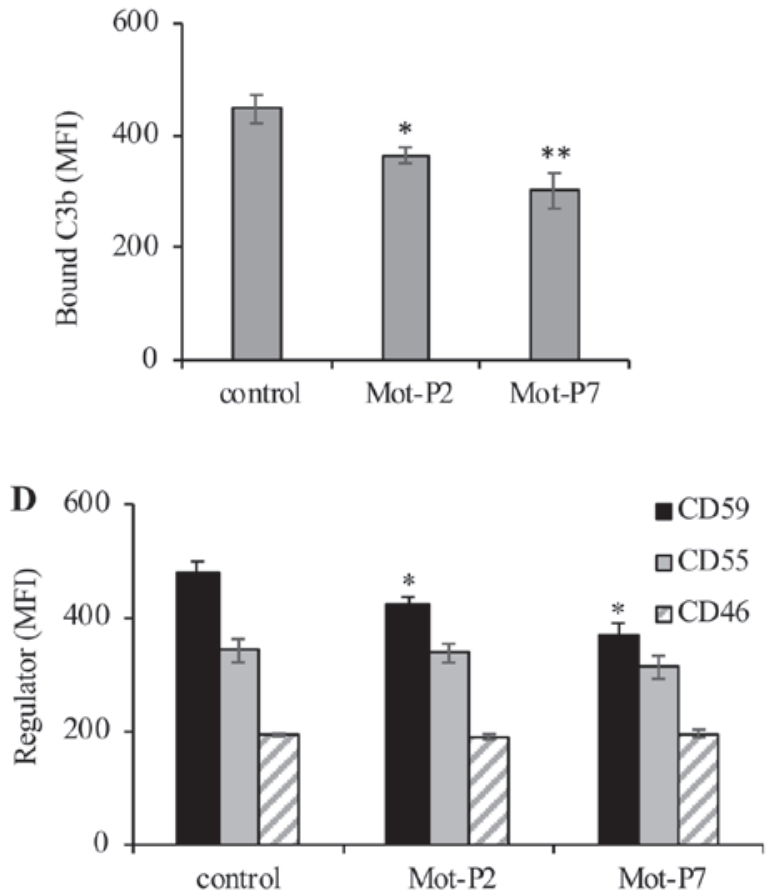

F

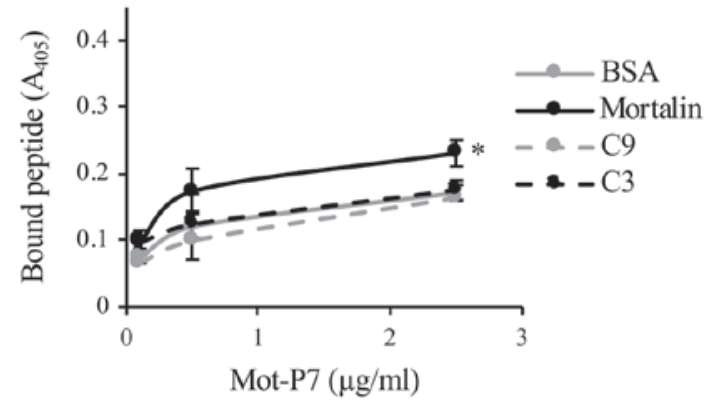

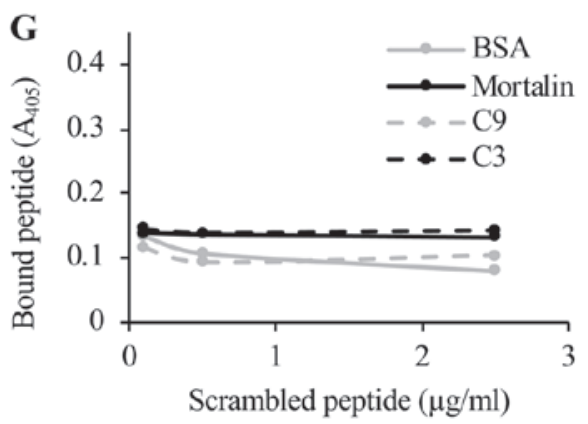

Figure 6. Combination of peptide- and complement-dependent cytotoxicity. (A) Ramos cells were treated with a sub-toxic dose of Mot-P2 or Mot-P7 (5 and $50 \mu \mathrm{M}$, respectively) or with DMSO for $30 \mathrm{~min}$ at $37^{\circ} \mathrm{C}$. Next, cells were treated with or without Rituximab (RTX, $2 \mu \mathrm{g} / \mathrm{ml}$ ) for $30 \mathrm{~min}$ at $4^{\circ} \mathrm{C}$ and with $50 \%$ NHS for $60 \mathrm{~min}$ at $37^{\circ} \mathrm{C}$. Cells were washed, labeled with PI and cell death was analyzed by flow cytometry. "P<0.05 vs. DMSO-treated control cells. (B) Ramos cells were treated with $5 \mu \mathrm{M}$ Mot-P2 or $50 \mu \mathrm{M}$ Mot-P7 or with DMSO for 30 min at $37^{\circ} \mathrm{C}$. To measure C3 deposition, cells were incubated with RTX $(1.5 \mu \mathrm{g} / \mathrm{ml})$ for $30 \mathrm{~min}$ at $4{ }^{\circ} \mathrm{C}$ and further incubated with $50 \% \mathrm{NHS}$ for $10 \mathrm{~min}$ at $37^{\circ} \mathrm{C}$. Cells were washed, treated with goat anti-C 3 antibodies followed by FITC-conjugated rabbit anti-goat IgG antibodies and analyzed by flow cytometry. ${ }^{*} \mathrm{P}<0.05$ and ${ }^{* *} \mathrm{P}<0.01$ vs. DMSO-treated control cells. (C) Ramos cells were treated $5 \mu \mathrm{M}$ Mot-P2 or $50 \mu \mathrm{M}$ Mot-P7 or with DMSO (control) for 30 min at $37^{\circ} \mathrm{C}$. To measure C5b-9 (MAC) deposition level, cells were incubated with $2 \mu \mathrm{g} / \mathrm{ml} \mathrm{RTX}$ for $30 \mathrm{~min}$ at $4^{\circ} \mathrm{C}$, followed by treatment with $50 \% \mathrm{NHS}$, for $10 \mathrm{~min}$ at $37^{\circ} \mathrm{C}$. Next, cells were washed and treated or not with trypsin $(100 \mu \mathrm{g} / \mathrm{ml})$ for $20 \mathrm{~min}$ at room temperature. Then, cells were labeled with mouse anti-C5b-9 neo-epitope antibody aE11 followed by FITC-conjugated goat anti-mouse IgG antibodies. Cells were analyzed by flow cytometry. ${ }^{*} \mathrm{P}<0.05$ and ${ }^{* *} \mathrm{P}<0.01$ vs. control cells. (D) Ramos cells were treated with $5 \mu \mathrm{M}$ Mot-P2 or $50 \mu \mathrm{M}$ Mot-P7 or with DMSO (control) for $30 \mathrm{~min}$ at $37^{\circ} \mathrm{C}$. To determine the expression level of the membrane complement regulatory proteins, cells were labeled with mouse anti-CD46, anti-CD55 or anti-CD59 antibodies, followed by FITC-conjugated goat anti-mouse IgG antibodies and analyzed by flow cytometry. "P<0.05 vs. DMSO-treated control cells. (E-G) Purified h uman mortalin, C9, C3 or BSA ( $5 \mu \mathrm{g} / \mathrm{ml}$ each) was attached overnight to wells of a 96-well plate at $4^{\circ} \mathrm{C}$. Next, wells were washed and blocked with $1 \% \mathrm{BSA}$ for $1 \mathrm{~h}$ at room temperature followed by adding to the wells biotinylated peptides (E) Mot-P2, (F) Mot-P7 or a (G) scrambled peptide $(0.5$ or $2.5 \mu \mathrm{g} / \mathrm{ml})$ for $1 \mathrm{~h}$ at room temperature. Wells were washed, treated with peroxidase-conjugated streptavidin for $1 \mathrm{~h}$ at room temperature. Bound peptides were quantified using TMB substrate and absorbance was read at $405 \mathrm{~nm}$ in a microplate reader. ${ }^{*} \mathrm{P}<0.05$ and ${ }^{* *} \mathrm{P}<0.01$ vs. BSA. MFI, mean fluorescence intensity; PI, propidium iodide; NHS, normal human serum; BSA, bovine serum albumin 
Table I. Similarities and differences in the mode of action of Mot-P2 and Mot-P7.

\begin{tabular}{|c|c|c|}
\hline Peptide characteristics & Mot-P2 & Mot-P7 \\
\hline $\mathrm{LD} 50, \mu \mathrm{M}^{\mathrm{a}}$ & $26-30$ & $40-63$ \\
\hline LDH release & + & + \\
\hline PS externalization & + & $t^{\mathrm{b}}$ \\
\hline $\mathrm{Ca}^{2+}$ entry dependence ${ }^{\mathrm{c}}$ & - & + \\
\hline Cholesterol protection $^{\mathrm{d}}$ & + & + \\
\hline MIMD $^{\mathrm{e}}$ & ++ & + \\
\hline ATP level drops & + & + \\
\hline ROS generated & + & + \\
\hline ROS involved in cell death ${ }^{\mathrm{f}}$ & - & + \\
\hline Cell growth inhibition ${ }^{\mathrm{g}}$ & + & + \\
\hline Cell cycle inhibition ${ }^{\mathrm{g}}$ & + & + \\
\hline Mortalin dependence & + & + \\
\hline Direct binding to mortalin & ++ & + \\
\hline Additive effect with $\mathrm{CDC}^{\mathrm{h}}$ & + & + \\
\hline
\end{tabular}

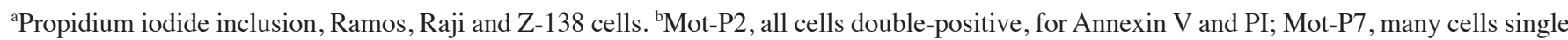
Annexin V-positive, some double positive. ${ }^{\mathrm{c}}$ Cytotoxicity inhibited by EGTA. ${ }^{\mathrm{d} C y t o t o x i c i t y ~ i n h i b i t e d ~ b y ~ M ~} \beta C D$ and filipin III. ${ }^{\mathrm{e}}$ Mitochondrial inner membrane depolarization. ${ }^{\mathrm{f}} \mathrm{N}$-acetyl cysteine inhibits cell death. ${ }^{\mathrm{g}} \mathrm{Tested}$ at a non-toxic peptide concentration. ${ }^{\mathrm{h} P e p t i d e}$ and complement have additive cytotoxic effects. ROS, reactive oxygen species; CDC, complement-dependent cytotoxicity; LDH, lactate dehydrogenase; LD, lethal dose.

with Mot-P2-treated cells. Furthermore, cell death induced by Mot-P7 was partially inhibited by chelation of extracellular calcium, which was not the case for Mot-P2. Calcium ions play a crucial role in cell death regulation and numerous pharmaceuticals target $\mathrm{Ca}^{2+}$-mediated processes (23). An increase in intracellular calcium is also essential to trigger plasma membrane remodeling and PS externalization (32). Mot-P7 may be able to use calcium ion influx for both PS externalization and further perforation of the plasma membrane. Subsequently, in absence of extracellular calcium ions, Mot-P7 may become less effective.

Plasma membrane is the initial cellular compartment with which the peptides interact. Cholesterol is known to influence plasma membrane damage by membrane-disrupting peptides or proteins in two ways. It may either serve as a receptor for them and facilitate membrane damage (33) or it may promote removal or blockade of the toxic molecules and protect the cells $(25,26)$. Membranes with higher cholesterol levels have a decreased rate of peptide insertion (34). In the present study, both depletion and blocking of cholesterol induced enhanced cell sensitivity to Mot-P2 and Mot-P7. Therefore, plasma membrane cholesterol may have a protective role for both peptides. However, whether cholesterol could facilitate peptide removal and/or membrane repair remains to be determined.

The second organelle affected by the peptides was the mitochondrion. This effect could be secondary to calcium influx or to another, yet undefined, toxic moiety or could be directly activated by peptides binding to the mitochondrial outer membrane. The results from confocal analysis revealed peptides accumulation inside the cytoplasm within 5 min following cell binding. This was more distinct with Mot-P2 than with Mot-P7. Furthermore, the mitochondrial membrane potential depolarization induced by Mot-P2 was higher than that of Mot-P7. The TAT sequence has been demonstrated to allow peptides passage through mitochondrial membranes via mechanisms that do not involve the regular import pathway (35). In addition, the ATP-depleting activity of Mot-P2 was more pronounced than that of Mot-P7. Both peptides induced ROS overproduction; however, ROS scavenging by NAC decreased Mot-P7-induced, but not Mot-P2-induced, cell death. Mot-P7 may be less effective without extracellular calcium ions. This may account for the dependence of Mot-P7 on ROS for cell death. Compared with Mot-P7, Mot-P2 induced a more rigorous and faster damage to the plasma membrane and the mitochondria and activated rapid cell death independent of calcium entry and ROS generation. Evaluating the combined action of Mot-P2 and Mot-P7 may therefore be of interest. It is possible that the effect of the two peptides may be additive or synergistic. However, because both peptides target mortalin in the cell, their combination might lead to reduction in their cytotoxic activity. Binding of one peptide to mortalin could delay the binding of the second peptide due to the possible competition or allosteric effect.

Since mortalin protects cells from CDC, the impact of Mot-P2 and Mot-P7 on CDC was also investigated in the present study. The results demonstrated that the peptides and CDC acted additively but not synergistically. Under the conditions used, the peptides had no effect on CD20 expression; however, they slightly decreased C3 deposition but had no effect on C5b-9 membrane insertion. The elevated cell death may therefore not result from peptide-induced enhanced complement activation. The additive cytotoxicity of the peptides and C5b-9 could result from one or more of the following effects. Firstly, the peptide could target mortalin in the cells and block its protective activity against CDC, 
enhancing therefore CDC. In this respect, direct binding of Mot-P2 and Mot-P7 to mortalin is shown. In addition, the peptides are both derived from the nucleotide-binding domain of mortalin, known to bind complement C8 and C9 and inhibit CDC (14). Secondly, the peptides could bind to essential mortalin binders and therefore sensitize cells to CDC. Thirdly, the lytic signals of C5b-9 could amplify the toxic effects of the peptides. Fourthly, the two cell death pathways could act independently, and the resulting additive cell death could reflect the cumulative damage they inflicted on the target cells. Further investigation is required to determine whether the actions of the peptides and the antibody/complement are dependent or independent. However, when considering cancer therapy, even as combined monotherapies, they may have an advantage over each monotherapy given alone $(36,37)$.

In conclusion, the present study demonstrated that the two mortalin-TAT peptides were highly cytotoxic to numerous cancer cell types. The peptides acted as single agents but also exhibited additive cytotoxicity when combined with antibody-mediated complement-dependent cytotoxicity. They may therefore be considered as valuable anti-cancer biotherapies. Peptide-based therapeutics for cancer have their pros and cons, and numerous attempts have been made to leverage their cytotoxicity and to overcome some of these challenges $(38,39)$. The use of Mot-P2 or Mot-P7 as monotherapy for cancer may be even more effective when combined with anti-cancer antibodies. It may improve the clinical efficacy while maintaining acceptable clinical toxicity. Combination therapy also leads to reduced side effects, since lower dosage of each drug is required. Subsequently, these two peptides may stop cell cycle, when sub-toxic doses are applied. Furthermore, the high efficacy of combination therapy may produce a more effective response, in fewer cycles of treatment; this option may therefore reduce drug resistance incidence (40).

\section{Acknowledgements}

Not applicable.

\section{Funding}

This study was supported by the Israel Cancer Association (grant no. 20150110) and The Varda and Boaz Dotan Research Center in Hemato-Oncology (Tel Aviv University; grant no. 060141520).

\section{Availability of data and materials}

The datasets used and/or analyzed during the present study are available from the corresponding author on reasonable request.

\section{Authors' contributions}

ZF designed the study. RJ and ZF wrote the article. RJ performed most of the experiments. AW performed the experiments with the carcinoma cell lines. MS, LZ and ND contributed to some of the experiments. OB collected the clinical samples. All authors read and approved the final manuscript.

\section{Ethics approval and consent to participate}

This study was approved by the Helsinki Committee of the Rabin Medical Center, Petach Tikva, Israel and informed consent was provided by all participants.

\section{Patient consent for publication}

Not applicable.

\section{Competing interests}

The authors declare that they have no competing interests

\section{References}

1. Hanahan D and Weinberg RA: Hallmarks of cancer: The next generation. Cell 144: 646-674, 2011.

2. Ran Q, Wadhwa R, Kawai R, Kaul SC, Sifers RN, Bick RJ, Smith JR and Pereira-Smith OM: Extramitochondrial localization of mortalin/mthsp70/PBP74/GRP75. Biochem Biophys Res Commun 275: 174-179, 2000.

3. Wadhwa R, Yaguchi T, Hasan MK, Mitsui Y, Reddel RR and Kaul SC: Hsp70 family member, mot-2/mthsp70/GRP75, binds to the cytoplasmic sequestration domain of the p53 protein. Exp Cell Res 274: 246-253, 2002.

4. Dundas SR, Lawrie LC, Rooney PH and Murray GI: Mortalin is over-expressed by colorectal adenocarcinomas and correlates with poor survival. J Pathol 205: 74-81, 2005.

5. Takano S, Wadhwa R, Yoshii Y, Nose T, Kaul SC and Mitsui Y: Elevated levels of mortalin expression in human brain tumors. Exp Cell Res 237: 38-45, 1997.

6. Ando K, Oki E, Zhao Y, Ikawa-Yoshida A, Kitao H, Saeki H, Kimura Y, Ida S, Morita M, Kusumoto T, et al: Mortalin is a prognostic factor of gastric cancer with normal p53 function. Gastric Cancer 17: 255-262, 2014.

7. Wadhwa R, Takano S, Kaur K, Deocaris CC, Pereira-Smith OM, ReddelRR and Kaul SC: Upregulation of mortalin/mthsp70/Grp75 contributes to human carcinogenesis. Int J Cancer 118: 2973-2980, 2006.

8. Rozenberg P, Kocsis J, Saar M, Prohászka Z, Füst G and Fishelson Z: Elevated levels of mitochondrial mortalin and cytosolic HSP70 in blood as risk factors in patients with colorectal cancer. Int J Cancer 133: 514-518, 2013.

9. Jubran R, Kocsis J, Garam N, Maláti É, Gombos T, Barabás L, Gráf L, Prohászka Z and Fishelson Z: Circulating mitochondrial stress 70 protein/mortalin and cytosolic Hsp70 in blood: Risk indicators in colorectal cancer. Int J Cancer 141: 2329-2335, 2017.

10. Kaul SC, Deocaris CC and Wadhwa R: Three faces of mortalin: A housekeeper, guardian and killer. Exp Gerontol 42: 263-274, 2007.

11. Voisine C, Craig EA, Zufall N, von Ahsen O, Pfanner N and Voos W: The protein import motor of mitochondria: Unfolding and trapping of preproteins are distinct and separable functions of matrix Hsp70. Cell 97: 565-574, 1999.

12. Pilzer D and Fishelson Z: Mortalin/GRP75 promotes release of membrane vesicles from immune attacked cells and protection from complement-mediated lysis. Int Immunol 17: 1239-1248, 2005.

13. Pilzer D, Saar M, Koya K and Fishelson Z: Mortalin inhibitors sensitize K562 leukemia cells to complement-dependent cytotoxicity. Int J Cancer 126: 1428-1435, 2010.

14. Saar Ray M, Moskovich O, Iosefson O and Fishelson Z: Mortalin/GRP75 binds to complement $C 9$ and plays a role in resistance to complement-dependent cytotoxicity. J Biol Chem 289: 15014-15022, 2014.

15. Frankel AD and Pabo CO: Cellular uptake of the tat protein from human immunodeficiency virus. Cell 55: 1189-1193, 1988.

16. Raucher D and Ryu JS: Cell-penetrating peptides: Strategies for anticancer treatment. Trends Mol Med 21: 560-570, 2015.

17. Darzynkiewicz Z, Juan G and Bedner E: Determining cell cycle stages by flow cytometry. Curr Protoc Cell Biol Chapter 8: Unit 8 4, 2001.

18. Smiley ST, Reers M, Mottola-Hartshorn C,Lin M, Chen A,Smith TW, Steele GD Jr and Chen LB: Intracellular heterogeneity in mitochondrial membrane potentials revealed by a J-aggregate-forming lipophilic cation JC-1. Proc Natl Acad Sci USA 88: 3671-3675, 1991. 
19. Vivès E, Brodin P and Lebleu B: A truncated HIV-1 Tat protein basic domain rapidly translocates through the plasma membrane and accumulates in the cell nucleus. J Biol Chem 272: 16010-16017, 1997.

20. Nagata S: Apoptosis and Clearance of Apoptotic Cells. Annu Rev Immunol 36: 489-517, 2018.

21. Hirt UA and Leist M: Rapid, noninflammatory and PS-dependent phagocytic clearance of necrotic cells. Cell Death Differ 10: 1156-1164, 2003.

22. Caserta TM, Smith AN, Gultice AD, Reedy MA and Brown TL: Q-VD-OPh, a broad spectrum caspase inhibitor with potent antiapoptotic properties. Apoptosis 8: 345-352, 2003.

23. Zhivotovsky B and Orrenius S: Calcium and cell death mechanisms: A perspective from the cell death community. Cell Calcium 50: 211-221, 2011.

24. Mason AJ, Marquette A and Bechinger B: Zwitterionic phospholipids and sterols modulate antimicrobial peptide-induced membrane destabilization. Biophys J 93: 4289-4299, 2007.

25. Prenner EJ, Lewis RNAH, Jelokhani-Niaraki M, Hodges RS and McElhaney RN: Cholesterol attenuates the interaction of the antimicrobial peptide gramicidin $\mathrm{S}$ with phospholipid bilayer membranes. Biochim Biophys Acta 1510: 83-92, 2001.

26. Moskovich O, Herzog LO, Ehrlich M and Fishelson Z: Caveolin-1 and dynamin-2 are essential for removal of the complement C5b-9 complex via endocytosis. J Biol Chem 287: 19904-19915, 2012.

27. Liu Y, Liu W, Song XD and Zuo J: Effect of GRP75/mthsp70/ PBP74/mortalin overexpression on intracellular ATP level, mitochondrial membrane potential and ROS accumulation following glucose deprivation in PC12 cells. Mol Cell Biochem 268: 45-51, 2005.

28. Sun SY: N-acetylcysteine, reactive oxygen species and beyond. Cancer Biol Ther 9: 109-110, 2010.

29. Moskovich O and Fishelson Z: Quantification of complement C5b-9 binding to cells by flow cytometry. In: The Complement System: Methods and Protocols. 1100th edition. Gadjeva M (ed). Humana Press, Totowa, NJ, pp103-108, 2014.

30. Bhakdi S, Tranum-Jensen J and Klump O: The terminal membrane C5b-9 complex of human complement. Evidence for the existence of multiple protease-resistant polypeptides that form the trans-membrane complement channel. J Immunol 124: $2451-2457,1980$.
31. Koya K, Li Y, Wang H, Ukai T, Tatsuta N, Kawakami M, Shishido and Chen LB: MKT-077, a novel rhodacyanine dye in clinical trials, exhibits anticarcinoma activity in preclinical studies based on selective mitochondrial accumulation. Cancer Res 56: 538-543, 1996.

32. Kunzelmann-Marche C, Freyssinet JM and Martínez MC: Regulation of phosphatidylserine transbilayer redistribution by store-operated $\mathrm{Ca} 2+$ entry: Role of actin cytoskeleton. J Biol Chem 276: 5134-5139, 2001.

33. Heuck AP, Moe PC and Johnson BB: The cholesterol-dependent cytolysin family of gram-positive bacterial toxins. Subcell Biochem 51: 551-577, 2010.

34. Won A, Ruscito A and Ianoul A: Imaging the membrane lytic activity of bioactive peptide latarcin 2a. Biochim Biophys Acta 1818: 3072-3080, 2012.

35. Del Gaizo V, MacKenzie JA and Payne RM: Targeting proteins to mitochondria using TAT. Mol Genet Metab 80: 170-180, 2003.

36. Palmer AC and Sorger PK: Combination cancer therapy can confer benefit via patient-topatient variability without drug additivity or synergy. Cell 171: 1678-1691.e13, 2017.

37. Foucquier J and Guedj M: Analysis of drug combinations: Current methodological landscape. Pharmacol Res Perspect 3: $\mathrm{e} 00149,2015$.

38. Kurrikoff K, Aphkhazava D and Langel Ü: The future of peptides in cancer treatment. Curr Opin Pharmacol 47: 27-32, 2019.

39. Guidotti G, Brambilla L and Rossi D: Peptides in clinical development for the treatment of brain tumors. Curr Opin Pharmacol 47: 102-109, 2019.

40. Bayat Mokhtari R, Homayouni TS, Baluch N, Morgatskaya E, Kumar S, Das B and Yeger H: Combination therapy in combating cancer. Oncotarget 8: 38022-38043, 2017. 